\title{
Tapia's Syndrome
}

\author{
Shadaab Mumtaz, MFDS RCPS(Glasg),* Alastair Henry, MRCS, $\uparrow$ and Mark Singh, FRCS \\ (OMFS)* \\ *Mid Essex Hospitals Trust, Chelmsford, United Kingdom, and †Princess of Wales Hospital, Bridgend, United Kingdom
}

More than 100,000 general anesthetic procedures are conducted in United Kingdom every year for dental interventions, according to large survey of the National Health Services. ${ }^{1}$ The risk of mortality has reduced considerably in the past few decades because of the use of safe and effective techniques. However, adverse effects still exist and are dependent on patient, environmental, and operator factors. We present an uncommon complication of intubation that merits due awareness.

Key Words: Tapia's; Hypoglossal nerve palsy; Vagus nerve palsy; Dysphonia; Hoarseness.

A 23-year-old male patient undergoing a routine postoperative examination was found to have deviation of the tongue to the right side as well as dysphonia (Figure).

Eleven days previously, he underwent surgical removal of the upper right wisdom tooth leading to a large oroantral communication. The patient had postoperative oral bleeding and epistaxis, which was uncontrolled with local/hemostatic measures. An emergency general anesthetic procedure was carried out to control hemorrhage with placement of bilateral nasal packing. Postoperative extended endotracheal intubation for 4 days was required. No other neurological deficit was noted apart from the above features.

He was diagnosed with Tapia's syndrome, and careful supportive monitoring was prescribed along with speech therapy and dietary support. The patient showed signs of early recovery, with complete resolution in 3 months' time.

\section{DISCUSSION}

Concomitant hypoglossal and vagus nerve injuries after intubation are very uncommon but well documented in the literature. It was first described by A. G. Tapia in $1905 .^{2}$ The other commonly associated features include reduced tongue motility and swallowing difficulties.

Received February 19, 2018; accepted for publication April 11, 2018.

Address correspondence to Dr Shadaab Mumtaz, Oral and Maxillofacial Surgery Department, Broomfield Hospital, Court Road, Chelmsford CM1 7ET, UK; Shadaab@me.com.

Anesth Prog 65:129-130 2018 | DOI 10.2344/anpr-65-04-06

(C) 2018 by the American Dental Society of Anesthesiology
Dearing ${ }^{3}$ presented a case of hypoglossal nerve palsy after dental extraction under general anesthesia. Similar pathology has been noted after fixation of a fractured mandible ${ }^{4}$ and orthognathic surgery. ${ }^{5}$ The literature suggests that almost all of these presentations were transient and showed significant improvement within 3 months, which was true for our case as well.

Although the pathogenesis is unclear, the following risk factors have been suggested:

- Incorrect use of laryngoscope

- Increased neck hyperextension

- Prolonged pressure on the trachea due to overinflation of cuff

- Prolonged compression from throat packs

To our knowledge, only 1 case of a central lesion causing Tapia's syndrome has been described in the literature, with the remaining reported to be due to peripheral causes, as listed above. ${ }^{6}$ The hypoglossal nerve is found to be particularly vulnerable near the greater cornu of hyoid bone because of compression/ neuropraxic injury from an overinflated cuff. ${ }^{7}$ Vagus nerve injury is most likely a combination of pressure and stretching of nerve on its pathway as it supplies the epiglottis and supraglottic area. Both of these nerves cross each other near the transverse process of the first cervical vertebra, and cervical hyperextension is thought to stretch both these nerves, causing neuropraxia. ${ }^{8}$

In conclusion, we recommend increased care by anesthetic and surgical teams to prevent such complications. As the diagnosis is clinical, cumbersome, and expensive, investigations should be avoided. The patient should be reassured that the vast majority of cases resolve without specific treatment. Allied health profes- 


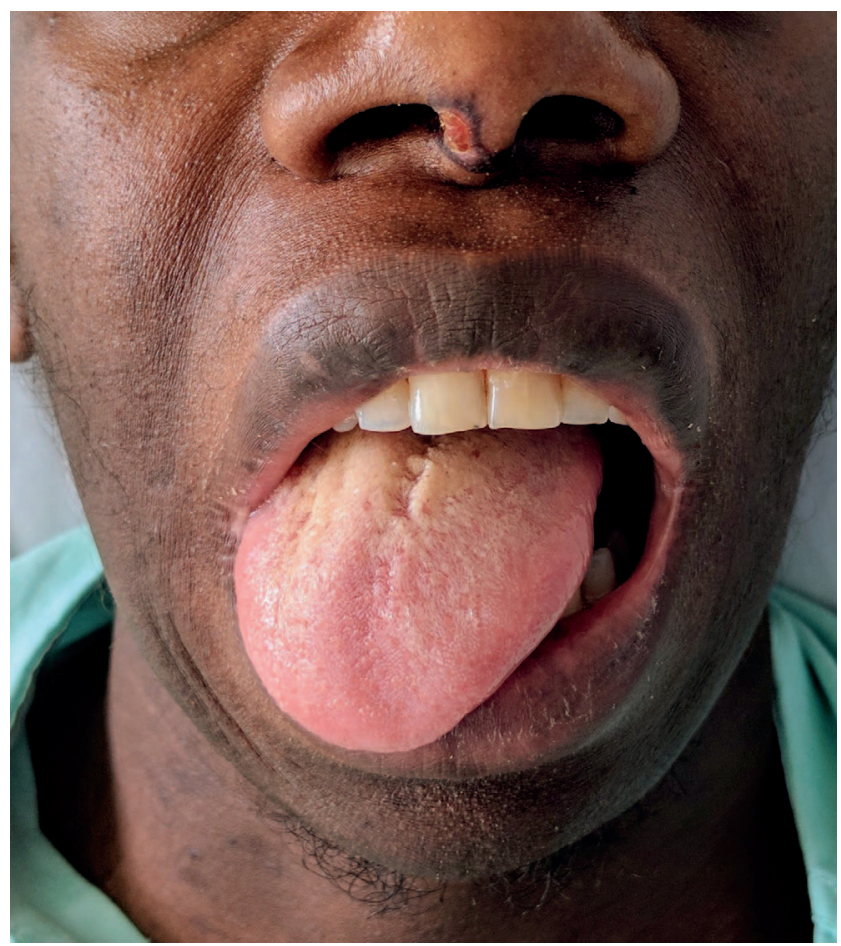

Deviation of the tongue to the right side and dysphonia.

sionals assisting with deglutition and nutrition play an important role during recovery. Our aim is to increase awareness and understanding of this rare self-limiting condition.

\section{REFERENCES}

1. Hong B, Baker A. General anaesthetic service for adult dental extractions: an 'À La Carte Menu'? Survey results. $\mathrm{Br}$ Dent J. 2017;222:261-267.

2. Tapia AG. Un caso de paralisis del lado derecho de la laringe y de ungue, con paralisis del externo-cleidomastoidea y trapecio del mismo lado. Siglo Medica. 1905;52:211213.

3. Dearing J. Transient contralateral nerve palsy following third molar surgery under day-case general anaesthesia: a case report and review of the literature. Br J Oral Maxillofac Surg. 1998;36:24-26.

4. Kashyap SA, Patterson AR, Loukota RA, Kelly G. Tapia's syndrome after repair of a fractured mandible. $\mathrm{Br} J$ Oral Maxillofac Surg. 2010;48:53-54.

5. Ota N, Izumi K, Okamoto Y, Toshitani K, Nakayama K, Fukuzawa H, Ozeki S, Ikebe T. Tapia's syndrome following the orthognathic surgery under general anaesthesia. J Oral Maxillofac Surg Med Pathol. 2013;25:52-54.

6. Krasnianski M, Neudecker S, Schluter A, Krause U, Winterholler M. Central Tapia's syndrome ("matador's disease") caused by metastatic hemangiosarcoma. Neurology. 2003;61:868-869.

7. Brain A. Course of the hypoglossal nerve in relation to the position of the laryngeal mask airway. Anaesthesia 1995; 50:82-83.

8. Wadełek J, Kolbusz J, Orlicz P, Staniaszek A. Tapia's syndrome after arthroscopic shoulder stabilisation under general anaesthesia and LMA. Anaesthesiol Intensive Ther. 2012;44:31-34. 